\title{
Modelo para avaliação de desempenho: aplicação em um orçamento de uma obra de construção civil
}

\author{
Rogério Cabral de Azevedo ${ }^{\mathrm{a}}$, Leonardo Ensslin ${ }^{\mathrm{b}}$, Rogério Tadeu de Oliveira Lacerdac, \\ Lisiane Anderson Françad, Antônio Edésio Jungles ${ }^{e}$, Sandra Rolim Ensslin ${ }^{f}$ \\ a*cabral.razevedo@gmail.com, UFSC, Brasil \\ bleonardoensslin@gmail.com, UFSC, Brasil \\ crogerlacerda@gmail.com, UFSC, Brasil \\ dlisianefranca@yahoo.com.br, UFSC, Brasil \\ eajungles@gmail.com, UFSC, Brasil \\ fsensslin@gmail.com,UFSC, Brasil
}

\begin{abstract}
Resumo
Este trabalho consiste em uma abordagem exploratória de natureza prática que se utiliza dos problemas de desvios de orçamento apresentados por uma construtora brasileira como objeto de estudo, visando apresentar um processo para construir um modelo de avaliação multicritério com vistas a apoiar decisões quanto à orçamentação de uma obra de construção civil. Como instrumento de intervenção faz uso da metodologia multicritério de apoio à decisão - construtivista (MCDA-C), que conduziu à identificação, organização, mensuração e integração dos fatores julgados como relevantes de acordo com a percepção do decisor. Por fim, traz um estudo de caso que ilustra a construção do modelo e como este expandiu o conhecimento do decisor acerca do problema, evidenciando situações vulneráveis em seu processo orçamentário, oportunizando o desenvolvimento de ações de melhoria.
\end{abstract}

Palavras-chave

Avaliação de desempenho. Decisão. Construção civil. Gerenciamento de projetos.

\section{Introdução}

0 processo de orçar um empreendimento na construção civil é fator crítico para empresas construtoras (LOPES; LIBRELOTTO; AVILA, 2003), já que desvios significativos podem inviabilizar a continuidade da execução de uma obra ou impactar a lucratividade dessa atividade econômica que representa uma parcela considerável do produto interno bruto brasileiro e tem efeitos diretos na empregabilidade de pessoal (INSTITUTO..., 2010).

0 produto final desse setor econômico caracteriza-se por representar um alto investimento para as empresas e para seus clientes (SZAJUBOK; ALENCAR; ALMEIDA, 2006), o que justifica constantes pesquisas para melhoria dessa atividade - fato evidenciado pela afirmativa de Frej e Alencar (2010), que ressaltam o fato de a indústria da construção civil ser conhecida por atrasos em seus procedimentos gerenciais.
Assim, diante da importância de se manter uma estimativa de custos adequada, garantindo a lucratividade da organização, surge a necessidade de se estruturar um processo consistente de orçamentação (LOPES; LIBRELOTTO; AVILA, 2003).

A fim de contribuir para o presente contexto, emerge a seguinte pergunta de pesquisa: Como avaliar a qualidade de um orçamento e se valer desse conhecimento para propor ações preventivas de desvios?

Este trabalho apresenta um processo para a construção de um modelo de apoio à decisão com vistas a avaliar o desempenho de um orçamento em uma construtora localizada no estado de Santa Catarina. Tal modelo permitiu à empresa identificar os fatores que influenciam os desvios de um orçamento, possibilitando atuar sobre suas causas a fim de 
minimizá-las ou até eliminá-las, servindo como base para propostas de melhorias em sua elaboração.

Dessa forma, os objetivos específicos do trabalho são:

- Apresentar uma metodologia de apoio à decisão que gere entendimento nos decisores sobre o contexto da orçamentação na construção civil; e

- Realizar um estudo de caso a fim de ilustrar os procedimentos utilizados pela metodologia para construir o modelo de avaliação de desempenho, com vistas a aferir a qualidade de um orçamento e apoiar as decisões dos gestores quanto aos aperfeiçoamentos necessários para o contexto estudado.

Assim, além desta introdução, este artigo está disposto em mais cinco seções. Na seção seguinte, é abordada a fundamentação teórica a respeito de avaliação de desempenho no setor de construção civil; na terceira encontra-se a metodologia de pesquisa aplicada; a quarta seção destina-se ao modelo construído; a quinta seção apresenta as considerações finais dos autores.

\section{Referencial teórico}

Nesta seção contextualiza-se o gerenciamento de projetos de construção civil.

\subsection{Gerenciamento de projetos de construção civil - contextualização}

Contribuir com o processo de tomada de decisão, melhorar a qualidade do seu produto e, ainda, melhorar o seu potencial competitivo são alguns dos gatilhos que fizeram com que o setor de construção civil voltasse sua atenção às práticas de gerenciamento de projetos (WINTER; CHECKLAND, 2003).

Um projeto de construção civil apresenta algumas particularidades instigantes, entre elas: seu caráter não homogêneo e não seriado de produção, resultado da singularidade do produto normalmente feito sob encomenda; dependência de fatores climáticos durante seu processo construtivo; período de desenvolvimento relativamente longo; e a divisão da responsabilidade entre várias empresas (FREJ; ALENCAR, 2010). Tais características intrínsecas ao setor de construção civil exigem um gerenciamento de projetos eficiente e eficaz.

Casos de sucesso na gestão de projetos têm sido normalmente atribuídos à qualidade e à importância dadas à fase de planejamento, sendo que o planejamento com foco em orçamentação e cronograma tem fomentado inúmeras discussões entre os pesquisadores da área (DVIR; LECHLER, 2004).
Assumindo-se que o processo de orçar traduz parte do planejamento de um projeto, tem-se essa atividade vista de forma desafiadora pelas empresas, uma vez que cada empreendimento tem seu projeto único com condições locais, estrutura organizacional e cadeia de suprimentos distinta dos demais projetos (COSTA et al., 2006).

Face a essas características, o processo de orçamentação na construção civil é entendido pelos autores da presente pesquisa como um contexto complexo, conflituoso e incerto (LACERDA; ENSSLIN; ENSSLIN, 2011b).

Em suma, trata-se de um contexto no qual os decisores têm dificuldade em visualizar o impacto das suas decisões em um contexto global.

À luz dessa oportunidade de pesquisa, torna-se relevante conceituar qual a definição de avaliação de desempenho a ser utilizada no presente trabalho e como esse conceito vem ao encontro do contexto apresentado de gestão de projetos na construção civil.

\subsection{Conceito de avaliação de desempenho}

0 processo de avaliar o desempenho possibilita ao decisor compreender o contexto avaliado, habilitando-o dessa forma a realizar a tomada de decisão ciente dos impactos gerados pelas alternativas selecionadas, respeitando o seu juízo de valor.

Dentre os artigos selecionados para compor o referencial bibliográfico desta pesquisa, levantaram-se os conceitos sobre avaliação de desempenho (AD):

- Pollack-Johnson e Liberatore (2006) explicitam que a avaliação de desempenho está relacionada à duração e ao custo da tarefa, observando-se o critério de qualidade de execução das tarefas;

- Farris et al. (2006) entendem a avaliação de desempenho como uma tarefa que possibilita ao departamento ter novos insights sobre o impacto das mudanças no tempo de duração do projeto, por meio da aplicação de um índice que considera tanto a duração do projeto quanto as variáveis de entrada;

- Kapliński (2008) menciona que os métodos para auxiliar a tomada de decisão exigem o emprego de ferramentas de apoio de tecnologia de informação,

- Para Fan, Lin e Sheu (2008), essa atividade avalia variáveis dos riscos do projeto que sejam consideradas relevantes;

- Banaitiene et al. (2008) entendem que a avaliação de desempenho deve se basear em uma metodologia multicritério para apoiar a avaliação e seleção de alternativas que impactem o ciclo de vida de um edifício, empregando para isso critérios quali-quantitativos; 
- Cioffi e Khamooshi (2009) entendem que esse processo deve estar baseado na mensuração de riscos identificados em projetos passados, junto a um modelo matemático, a fim de determinar a probabilidade e os valores associados a esses riscos em projetos futuros;

- Para Koo et al. (2010), a avaliação de desempenho deve, mediante a utilização de informações precisas sobre os fatores críticos, potencializar o fator competitivo da indústria da construção.

Sustentados pelos conceitos reconhecidos na literatura, os autores desta pesquisa evoluem no entendimento da $\mathrm{AD}$, compreendendo a avaliação de desempenho como sendo:

[...] o processo para construir conhecimento no decisor, a respeito do contexto específico que se propõe avaliar, a partir da percepção do próprio decisor por meio de atividades que identificam, organizam, mensuram ordinalmente e cardinalmente, e sua integração e os meios para visualizar o impacto das ações e seu gerenciamento [...] (LACERDA; ENSSLIN; ENSSLIN, 2012).

À luz do conceito exposto, emergem as lentes pelas quais a revisão da literatura é executada, detalhadas nas cinco subseções seguintes.

\subsubsection{Identificação dos aspectos relevantes}

A primeira lente de pesquisa extraída do conceito exposto refere-se à identificação do que é relevante para o decisor, dentro do contexto avaliado. Com base no referencial teórico, foram encontradas diferentes formas para identificar os aspectos relevantes.

Pollack-Johnson e Liberatore (2006) consideram que a qualidade, o custo e o tempo de execução de cada etapa de um projeto constituem os aspectos relevantes a serem avaliados.

Para Fan, Lin e Sheu (2008), os aspectos relevantes são relacionados a eventos de risco, avaliados sob três perspectivas: i) capacidade de controlar o risco do projeto; ii) custos associado ao gerenciamento do risco; e iii) características do projeto.

Já Cioffi e Khamooshi (2009) entendem como aspectos relevantes os riscos ou falhas registrados em projetos anteriores.

De forma similar, Koo et al. (2010) identificam os aspectos relevantes sobre dados históricos e estabelecem a similaridade entre projetos como base para estimar o orçamento de um projeto na fase inicial do planejamento de negócios.

Uma ampliação em relação às pesquisas citadas anteriormente é apresentada nos trabalhos de Farris et al. (2006) e kapliński (2008). Farris et al. (2006) identificam os aspectos relevantes consultando os gestores responsáveis, orientados pela ferramenta DEA (Data Envelopment Analysis), e em revisões da literatura de gerenciamento de projetos. Já Kapliński (2008) identificou os aspectos relevantes por meio de questionários aplicados a profissionais de engenharia civil e gerenciamento de construções. Essa pesquisa foi realizada na Polônia, em 2000 e em 2005.

Uma contribuição valiosa é encontrada na pesquisa de Banaitiene et al. (2008), que remete à identificação dos aspectos relevantes acerca do objeto avaliado aos valores dos envolvidos no processo, neste caso os clientes, e também à opinião de especialistas da área.

A metodologia MCDA-C, instrumento de intervenção adotada neste trabalho, orienta que o decisor esteja envolvido no processo de identificação dos aspectos relevantes a fim de que o modelo construído represente seus objetivos estratégicos.

\subsubsection{Mensuração dos aspectos relevantes}

Identificados os aspectos relevantes do contexto, avança-se para a segunda lente de pesquisa, associada às formas de mensuração desses aspectos.

Para Farris et al. (2006), Banaitiene et al. (2008) e Koo et al. (2010), a mensuração dos aspectos relevantes é realizada por meio de escalas ordinais, que mensuram as propriedades físicas do contexto, além de escalas de Likert.

Da mesma forma, a mensuração desses aspectos nos trabalhos de Fan, Lin e Sheu (2008) e Cioffi e Khamooshi (2009) ocorre pela aplicação de escalas ordinais e de Likert. A probabilidade de ocorrência de um evento de erro é mensurada através das escalas de Likert, e os impactos dos aspectos mensurados são associados a escalas ordinais.

No trabalho de Kapliński (2008) não é relatado explicitamente o emprego de escalas, mas, diante das afirmativas do autor, supõe-se que a mensuração dos aspectos relevantes seja realizada por escalas ordinais.

Já Pollack-Johnson e Liberatore (2006) utilizam escalas cardinais para mensurar os aspectos relevantes, pela associação das propriedades físicas do contexto a estas escalas.

Este estudo se baseia na construção de descritores para mensurar os aspectos relevantes, utilizando primeiramente escalas ordinais que atendam às seguintes propriedades (ENSSLIN, 2009): i) mensurabilidade; ii) operacionalidade; iii) homogeneidade; iv) inteligibilidade; v) permitir distinguir o desempenho melhor e pior; e vi) respeitar as propriedades das escalas ordinais.

Reconhecendo os limites de uso das escalas ordinais, este trabalho aplica processos científicos para transformar essas escalas em escalas cardinais, 
a fim de permitir a comparação de um determinado nível de desempenho em um dado critério com o mesmo nível de desempenho em outro indicador.

Assim, torna-se possivel apresentar um processo que permite a integração das escalas de mensuração e que respeita os limites das escalas ordinais, utilizando-as apenas para operações matemáticas de frequência, contagem, mediana e moda (BARZILAl, 2001).

\subsubsection{Integração das escalas}

A terceira lente de pesquisa, a integração das escalas, objetiva oportunizar a integração das escalas de forma a obter uma visão global do objeto de avaliação.

A aplicação de formulações matemáticas para a integração das escalas é encontrada em três trabalhos.

Farris et al. (2006) realizam a integração pelo emprego da ferramenta DEA (Data Envelopment Analysis), a qual determina a variável de saída, que, no caso estudado, refere-se à duração do projeto.

Para Cioffi e Khamooshi (2009), a integração é concretizada por média ponderada, resultante da razão entre a soma das ocorrências nas escalas ordinais e o número máximo de eventos. De forma similar, Fan, Lin e Sheu (2008) aplicam funções que consideram as variáveis de risco históricas a fim de estimar o custo final do risco associado ao projeto avaliado.

Esses três trabalhos denotam a aplicação de operações matemáticas com escalas ordinais, ignorando suas limitações quanto a esse uso.

A utilização de pesos para balancear o quanto cada aspecto impacta no contexto global avaliado é encontrada nos trabalhos de Banaitiene et al. (2008) e Koo et al. (2010). Em Banaitiene et al. (2008), a integração é alcançada pela aplicação de uma matriz de normalização que considera os valores e pesos de cada aspecto segundo as preferências externadas pelo decisor, e para Koo et al. (2010), a integração das escalas é baseada em pesos calculados por algoritmos genéticos (GA) para compensação dos aspectos relevantes.

Já Pollack-Johnson e Liberatore (2006) utilizam escalas cardinais para a integração dos aspectos relativos a cada uma das etapas do processo construtivo, sendo a integração global final realizada através de programação linear.

Mesmo considerando o uso de pesos e de escalas cardinais uma evolução quando da integração das escalas, os autores (POLLACK-JOHNSON; LIBERATORE, 2006; BANAITIENE et al., 2008; KOO et al., 2010) o fazem sem associar essas taxas a níveis de referência, podendo assim comprometer o resultado do processo (KEENEY, 1992).
No trabalho apresentado por Kapliński (2008) não é mencionada a integração de escalas.

No presente trabalho, pretendendo dar maior acuracidade ao modelo de apoio à decisão, opta-se pela transformação da escala ordinal em intervalar. A escala de intervalos é obtida quando se tem todas as propriedades das escalas ordinais e se conhece a diferença de atratividade entre todos os níveis da escala. Assim, quando o conhecimento da escala é tão preciso que permite saber a distância entre todos os intervalos da escala, é atingido o grau de mensuração por intervalos e a escala passa a ser cardinal.

Caracterizada por uma unidade constante e comum de mensuração, uma escala intervalar atribui um valor real a todos os pares de objetos no conjunto ordenado. Keeney (1992), Bana e Costa et al. (1999), Ensslin, Dutra e Ensslin (2000), Ensslin et al. (2010) e Da Rosa et al. (2012) afirmam que a escala de intervalos pode ser obtida por meio da agregação de informações sobre a preferência do decisor em relação à diferença de atratividade de todos os níveis da escala ordinal.

\subsubsection{Diagnóstico da situação atual (SQ)}

A quarta lente de pesquisa trata do diagnóstico da situação atual do contexto avaliado. Em relação a esse ponto, a maior parte dos autores pesquisados, a saber, Banaitiene et al. (2008), Fan, Lin e Sheu (2008), Kaplinski (2008), Cioffi e Khamooshi (2009) e Koo et al. (2010) não fazem referência ao diagnóstico da situação atual em seus trabalhos.

Já nos trabalhos de Farris et al. (2006) e PollackJohnson e Liberatore (2006) é realizado o diagnóstico individual de cada aspecto avaliado (diagnóstico local). Farris et al. (2006) não apresentam a avaliação do desempenho global do objeto de avaliação, enquanto Pollack-Johnson e Liberatore (2006) realizam esse diagnóstico pela comparação dos valores realizados versus previstos.

No trabalho de Farris et al. (2006), o diagnóstico da situação atual é realizado pela comparação com valores de referência, obtidos a partir de um projeto benchmarking.

Para os autores do presente artigo, o diagnóstico da situação atual (status quo) deve ser tanto qualitativo quanto quantitativo e deve permitir a identificação gráfica da situação atual em cada um dos descritores do modelo e também de forma integrada, mensurando o desempenho atual da organização.

\subsubsection{Formas de aperfeiçoamento}

Dentre a revisão bibliográfica realizada, apenas o trabalho de Fan, Lin e Sheu (2008) apresenta uma 
proposta de avaliação de desempenho que promove alternativas de aperfeiçoamento. Os autores propõem um modelo matemático que auxilia os gerentes de projeto na definição de ações de resposta a riscos. Por meio desse modelo, os gerentes de projeto identificam e analisam alternativas, a fim de escolher estratégias para reduzir os riscos a um nível aceitável, levando em conta as características do projeto e a situação desses riscos, com o objetivo de melhorar o desempenho atual dos projetos.

Nos demais artigos selecionados, a saber, Farris et al. (2006), Pollack-Johnson e Liberatore (2006), Kapliński (2008), Banaitiene et al. (2008), Cioffi e Khamooshi (2009) e Koo et al. (2010), não foram discutidas explicitamente formas para melhorar o desempenho atual do contexto avaliado.

Para os autores deste estudo, busca-se compreender os impactos das ações potenciais nos objetivos julgados necessários e suficientes para a avaliação de um contexto.

\section{Metodologia de pesquisa}

Esta seção é dividida em três partes. Primeiramente apresenta-se o enquadramento metodológico. Em seguida são apresentados os procedimentos usados para a revisão da literatura. Por fim é discutido o instrumento de intervenção adotado.

\subsection{Enquadramento metodológico}

A pesquisa tem caráter exploratório, sendo aplicada e desenvolvida sob a forma de um estudo de caso. A fonte dos dados é de origem primária, sendo estes obtidos em entrevistas semiestruturadas na empresa foco do estudo, e o método de pesquisa é quali-quantitativo.

No tocante aos critérios de escolha do instrumento de intervenção adotado para a presente pesquisa, o estudo segue a linha de pensamento de Roy (1993) e Bana e Costa (1992), ao afirmarem que a metodologia a ser utilizada em um determinado contexto deve estar adequadamente alinhada com a problemática do apoio à decisão em questão.

Sobre as problemáticas do apoio à decisão, Roy (1996) as subdivide em dois grandes grupos: (i) as problemáticas do apoio à estruturação e (ii) as problemáticas do apoio à avaliação.

\subsubsection{As problemáticas do apoio à estruturação}

Para Bana e Costa (1992), as problemáticas de apoio à estruturação têm como características a compreensão do contexto decisório, o foco no entendimento do problema e a intenção de ser um norte para a criação de novas oportunidades de ação.

Com vistas a essas características da estruturação, Roy (1993) afirma que a lógica de investigação separa as abordagens de estruturação em dois grupos: (i) aqueles que assumem o posicionamento racionalista e (ii) aqueles que adotam o construtivismo como lógica de investigação.

Segundo Ensslin et al. (2010), a diferença crucial entre esses dois grupos se dá pelo reconhecimento dos limites da objetividade atendidos pela abordagem construtivista (LANDRY, 1995). Ou seja, o foco da estruturação, segundo o paradigma construtivista, se dá pela expansão e organização do conhecimento no decisor, enquanto o paradigma racionalista restringe a estruturação à etapa de formulação do modelo valendo-se de um entendimento universal das propriedades físicas do contexto decisório (ENSSLIN et al., 2010).

\subsubsection{As problemáticas do apoio à avaliação}

As problemáticas de apoio à avaliação são concebidas pelo ato de avaliar as ações de acordo com o desejo dos decisores, tendo-se em conta as características das ações (ROY, 1996). Sua operacionalização se dá por um instrumento de intervenção para tornar possível um determinado meio de avaliar as ações.

Para Roy (1993), essas problemáticas de apoio à avaliação podem ser classificadas em quatro tipos: (i) seleção - P $\alpha$; (ii) classificação - P $\beta$; (iii) ordenação

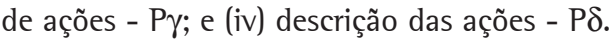

\subsubsection{As problemáticas do apoio à decisão e os instrumentos de intervenção disponíveis}

Alinhado à visão de mundo representada pelo conceito exposto na seção "Conceito de avaliação de desempenho", bem como aos paradigmas do apoio à decisão construtivista publicados por Lacerda, Ensslin e Ensslin (2011a) para avaliação do sucesso em projetos, o instrumento de intervenção adotado para este trabalho foi a metodologia multicritério de apoio à decisão - Construtivista (MCDA-C).

0 Quadro 1 resume a taxonomia das problemáticas do apoio à decisão, bem como as metodologias adequadas a cada uma delas, enquadrando a escolha da MCDA-C como o instrumento de intervenção adotado para a presente pesquisa.

\subsection{Revisão da literatura}

Para a revisão de literatura, foram adotados dois eixos de pesquisa: i) gerenciamento de projetos de construção civil; e ii) avaliação de desempenho. 
Quadro 1. Taxonomia das problemáticas do apoio à decisão e as metodologias adequadas a cada contexto decisório.

\begin{tabular}{|c|c|c|c|}
\hline Problemática & Grupo & Exemplo de metodologias & Exemplos de aplicação \\
\hline \multirow[t]{2}{*}{ Estruturação } & Racionalista & $\begin{array}{c}\text { MCDA } \\
\text { AHP } \\
\text { MAUT } \\
\text { MAVT } \\
\text { SMART }\end{array}$ & $\begin{array}{l}\text { Kumar Dey (2001), Cheung e Suen (2002), Xue, li, Shen et al. (2005), } \\
\text { Ai Lin Teo e Yean Yng Ling (2006), Oyetunji e Anderson (2006), } \\
\text { Güereca et al. (2007), Mateus, Ferreira e Carreira (2008), Mota, De } \\
\text { Almeida e Alencar (2009), Azad (2011) e Kog e Loh (2012) }\end{array}$ \\
\hline & Construtivista & MCDA-C & $\begin{array}{c}\text { Ensslin et al. (2010), Lacerda, Ensslin e Ensslin (2011a) e } \\
\text { Da Rosa et al. (2012) }\end{array}$ \\
\hline \multirow{4}{*}{ Avaliação } & Classificação & ELECTRE-TRI & $\begin{array}{c}\text { Szajubok, Mota e Almeida (2006), Krawczyńska (2008) e Almeida- } \\
\text { Dias, Figueira e Roy (2012) }\end{array}$ \\
\hline & Ordenação & $\begin{array}{l}\text { ELECTRE-11 } \\
\text { ELECTRE-111 } \\
\text { ELECTRE-IV }\end{array}$ & $\begin{array}{c}\text { Zavadskas, Ustinovichius e Stasiulionis (2004), Mota e De Almeida } \\
\text { (2007), Mota, De Almeida e Alencar (2009), Ulubeyli e Kazaz (2009), } \\
\text { Frenette et al. (2010) e Coronado et al. (2011) }\end{array}$ \\
\hline & Seleção & $\begin{array}{c}\text { ELECTRE-1 } \\
\text { ELECTRE-1S }\end{array}$ & $\begin{array}{c}\text { Anton e Grau (2004), Shanian e Savadogo (2009) e Stevovic, } \\
\text { Milovanovic e Milajic (2010) }\end{array}$ \\
\hline & Descrição & Soft Systems Methodology & Maqsood, Walker e Finegan (2007) e Sutrisna e Barrett (2007) \\
\hline
\end{tabular}

A base utilizada para o referencial foi a Web of Science, a qual constitui, na perspectiva dos autores da presente pesquisa, a base mais representativa, por fornecer o indicador JCR, o qual avalia a importância e relevância dos periódicos em âmbito mundial.

Para seleção dos artigos utilizou-se um processo estruturado de busca conforme exposto por Lacerda, Ensslin e Ensslin (2012), usando as palavras-chave project management, decision, project planning, management, construction management e budgeting. Todas conjugadas com a palavra-chave performance measurement, visando identificar os artigos com maior número de citações e que foram publicados após o ano de 2006.

Por meio da análise de títulos e resumos, foi possível realizar uma triagem dos artigos que estavam alinhados com o objeto de pesquisa. Após esse processo de triagem, foram selecionados sete artigos (FARRIS et al., 2006; POLLACK-JOHNSON; LIBERATORE, 2006; BANAITIENE et al., 2008; FAN; LIN; SHEU, 2008; KAPLIŃSKI, 2008; CIOFFI; KHAMOOSHI, 2009; K00 et al., 2010) que forneceram subsídios para a análise da literatura dos temas de pesquisa.

\subsection{Construção do modelo multicritério - procedimentos}

A construção do modelo multicritério de avaliação de desempenho sob a perspectiva da $\mathrm{m}-+$.

etodologia MCDA-C é dividida em três fases: i) Estruturação; ii) Avaliação; e iii) Recomendações (BANA E COSTA et al., 1999; DE MORAES et al., 2010; ENSSLIN et al., 2010; LACERDA; ENSSLIN; ENSSLIN, 2011b), como apresentado na Figura 1.

Cada uma das fases ilustradas na Figura 1 é detalhada durante o desenvolvimento do estudo de caso, apresentado a seguir.

\section{Modelo multicritério para avaliação de orçamentação em construção civil}

As próximas seções detalham os passos da construção do modelo de avaliação de orçamentação em construção civil.

\subsection{Estruturação do modelo}

$\mathrm{Na}$ fase de estruturação do problema foi utilizada a metodologia multicritério em Apoio à Decisão - Construtivista (MCDA-C) como proposto em Bana e Costa et al. (1999), Bortoluzzi, Ensslin e Ensslin (2010), Zamcopé et al. (2010), Da Rosa et al. (2011), Ensslin et al. (2010) e Lacerda, Ensslin e Ensslin (2010, 2011a, b).

\subsubsection{Contextualização}

Para iniciar a estruturação desse modelo, identificaram-se neste contexto o decisor, os atores com poder de interferência no processo e os atores influenciados pelas decisões a serem tomadas.

Esses atores foram identificados como: i) decisor: gerente de engenharia; ii) intervenientes: empresa de orçamentação executiva, engenheiros de obra, analista da qualidade e GestCon/UFSC; e iii) facilitadores: autores.

Ainda na fase de contextualização, foi definido um rótulo que representasse as principais preocupações fundamentais do decisor quanto ao problema, a saber: construir um modelo de avaliação de desempenho para apoiar decisões na orçamentação de obras de construção civil em uma construtora de Santa Catarina (BR).

\subsubsection{Estrutura hierárquica de valor}

As etapas para a obtenção da estrutura hierárquica de valor são detalhadas a seguir. 


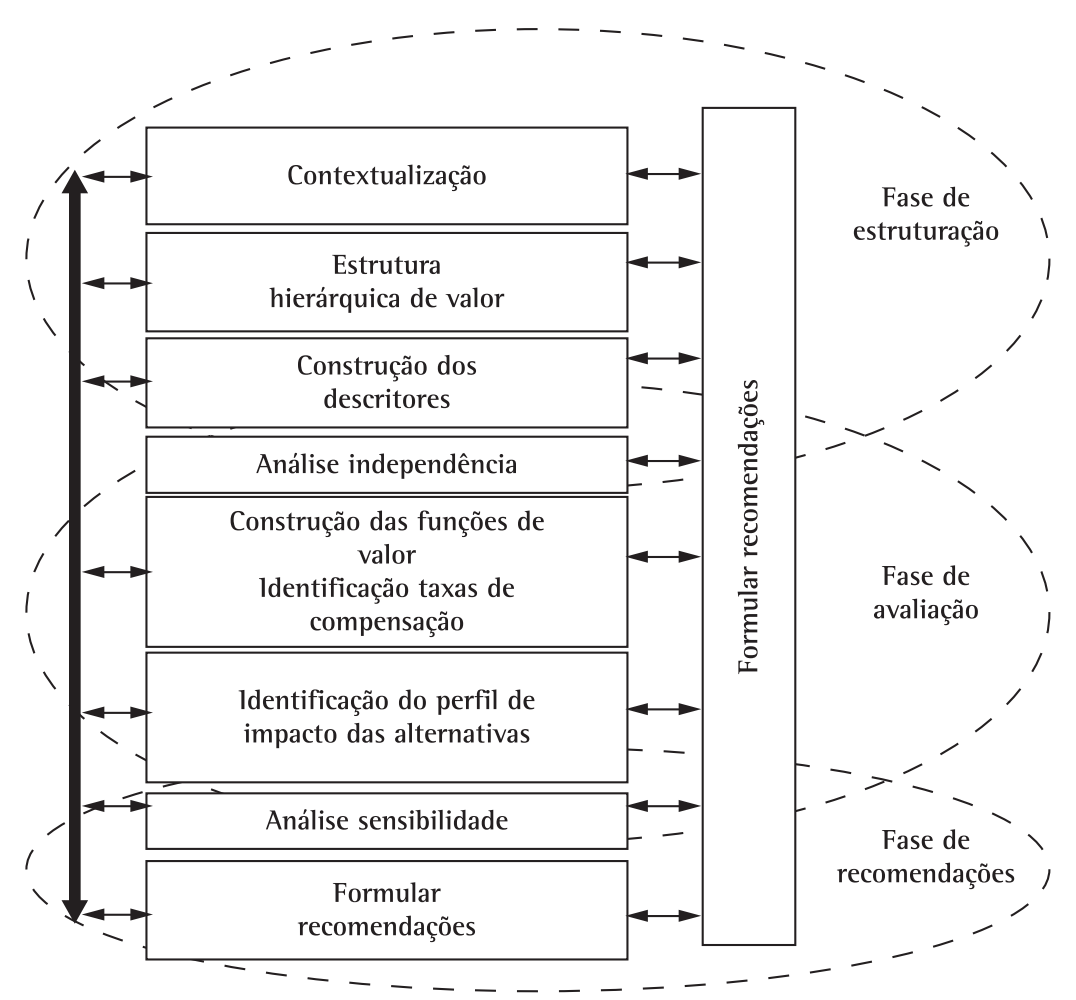

Figura 1. As fases da metodologia MCDA-C. Fonte: Lacerda, Ensslin e Ensslin (2011b).

\subsubsection{Elementos primários de avaliação e conceitos}

Nas entrevistas realizadas, o decisor foi estimulado a discorrer livremente sobre o problema a ser avaliado. As informações coletadas foram interpretadas possibilitando a identificação dos elementos primários de avaliação (EPAs), que representam o registro das principais propriedades do contexto avaliado que o decisor julga relevantes em função do objetivo pretendido. Dez dos 114 EPAs identificados são exibidos no Quadro 2.

Dando sequência, iniciou-se a construção de conceitos a partir dos EPAs. Os conceitos representam a expansão do entendimento dos EPAs, sendo que cada um deve estabelecer a direção de preferência do decisor (chamado polo presente) e também estabelecer a consequência que se deseja evitar ou minimizar (polo oposto psicológico).

Os dez conceitos construídos a partir dos EPAs são exibidos no Quadro 3. A reticência (“...”) deve ser lida como "ao invés de".

Como consequência dessa atividade, gerou-se um entendimento maior do contexto estudado, o que possibilitou aos facilitadores, em conjunto com o decisor, iniciar a identificação de objetivos estratégicos associados ao conhecimento construído.
Quadro 2. Relação de 10 EPAs identificados.

\begin{tabular}{|c|c|}
\hline EPA & Descrição \\
\hline 11 & Escolher mobiliário da área comum \\
\hline 12 & Escolher equipamentos da área comum \\
\hline 13 & Definir obras de arte para área comum \\
\hline 14 & Escolher utensílios para área comum \\
\hline 15 & Ter projeto de luminoteca de áreas comuns \\
\hline 16 & Especificar materiais para iluminação da área comum \\
\hline 17 & Ter projeto de jardinagem \\
\hline 18 & Definir plantas e outros itens \\
\hline 19 & Ter projeto de automação para área comum \\
\hline 20 & Especificar materiais e equipamentos de automação \\
\hline
\end{tabular}

Fonte: autoria própria.

Estabelecidos os objetivos estratégicos associados ao contexto, surge a necessidade de testar se esses objetivos atendem às propriedades de necessidade e suficiência frente aos conceitos anteriormente levantados.

Para atender a essas duas propriedades, o decisor relacionou cada conceito a um objetivo (necessidade), sendo que nenhum conceito ficou sem objetivo estratégico relacionado (suficiência).

A Figura 2 apresenta os objetivos estratégicos e a lista de todos os conceitos a eles relacionados, identificados neste estudo. 


\subsubsection{Construção dos descritores}

Nesta seção são apresentados os detalhes da etapa de construção dos descritores.

Mapas meios-fim e estrutura hierárquica de valor

Quadro 3. Os dez conceitos construídos a partir dos EPAs.

\begin{tabular}{|c|l|}
\hline Conceito & \multicolumn{1}{|c|}{ Descrição } \\
\hline C11 & $\begin{array}{l}\text { Garantir que projetos de áreas comuns sejam incluídos } \\
\text { no orçament...áreas comuns serem executadas com } \\
\text { parte do lucro previsto }\end{array}$ \\
\hline C12 & $\begin{array}{l}\text { Garantir a escolha (padrão ou defnição) do mobiliário } \\
\text { para orçamentação... Não prever verba no orçamento } \\
\text { para mobiliário }\end{array}$ \\
\hline C13 & $\begin{array}{l}\text { Garantir a escolha (padrão ou definição) de } \\
\text { equipamentos... incluir os custos ao final da obra }\end{array}$ \\
\hline C14 & $\begin{array}{l}\text { Garantir verba para a compra de obras de arte... Incluir } \\
\text { custos ao final da obra }\end{array}$ \\
\hline C15 & $\begin{array}{l}\text { Garantir a escolha (padrão ou definição) de utensílios... } \\
\text { lncluir os custos ao final da obra }\end{array}$ \\
\hline C16 & $\begin{array}{l}\text { Garantir a inclusão dos custos do projeto de luminotéca } \\
\text { no orçamento... Calcular os custos sem informações } \\
\text { reais }\end{array}$ \\
\hline C17 & $\begin{array}{l}\text { Ter materiais pré definidos para iluminação... Cada } \\
\text { empreendimento ter materiais para iluminação sem } \\
\text { padronização }\end{array}$ \\
\hline C18 & $\begin{array}{l}\text { Garantir a inclusão dos custos do projeto de jardinagem } \\
\text { no orçamento... Projeto de jardinagem executado com } \\
\text { parte do lucro previsto }\end{array}$ \\
\hline C19 & $\begin{array}{l}\text { Definir verba para projeto de jardinagem... Arcar com os } \\
\text { custos após a conclusão da obra }\end{array}$ \\
\hline C20 & $\begin{array}{l}\text { Garantir a inclusão dos custos do projeto de automação } \\
\text { no orçamento... Calcular os custos sem informações } \\
\text { reais }\end{array}$ \\
\hline
\end{tabular}

A construção dos mapas de relações meios-fim se iniciou com o decisor argumentando sobre cada conceito e como ele poderia ser alcançado (vínculos causais com outros conceitos), possibilitando identificar as possiveis ações aptas a gerar efeitos no desempenho dos objetivos subjacentes (EDEN; JONES; SIMMS, 1985; MONTIBELLER et al., 2008). Assim, é possível identificar linhas de argumentação que conduzem dos conceitos meios aos conceitos mais estratégicos.

A Figura 3 exibe o mapa de relações meios-fim para o objetivo estratégico "produtos e materiais" com seus clusters e subclusters nomeados.

Finalizada a construção dos mapas de relação meios-fim, a metodologia MCDA-C propõe que as estruturas de relações causais sejam transformadas e transportadas para a estrutura arborescente já elaborada anteriormente.

Nessa estrutura, denominada estrutura hierárquica de valor, se identificam os pontos de vista fundamentais (PVFs) e os pontos de vista elementares (PVEs). Para que isto seja feito, cada cluster deve ser validado para verificar se representa o contexto de forma a ser: essencial, controlável, completo, mensurável, operacional, isolável, não redundante, conciso e compreensível (KEENEY, 1992; ENSSLIN; MONTIBELLER; NORONHA, 2001).

A estrutura hierárquica de valor pode ser visualizada na Figura 4, onde se detalham os PVFs e PVEs do ponto de vista fundamental "produtos e materiais"

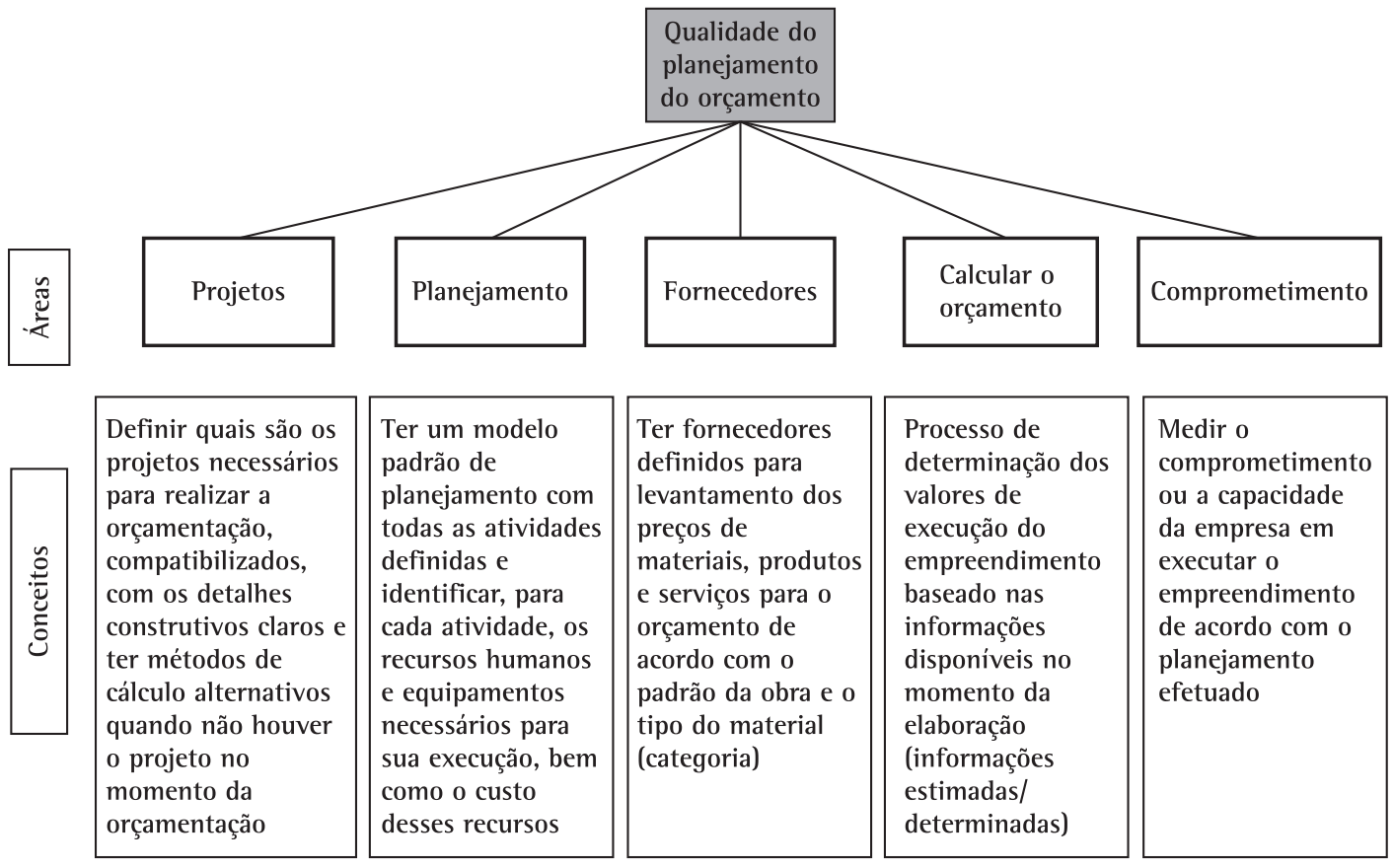

Figura 2. Estrutura top-down do modelo de avaliação e os conceitos a eles relacionados. 


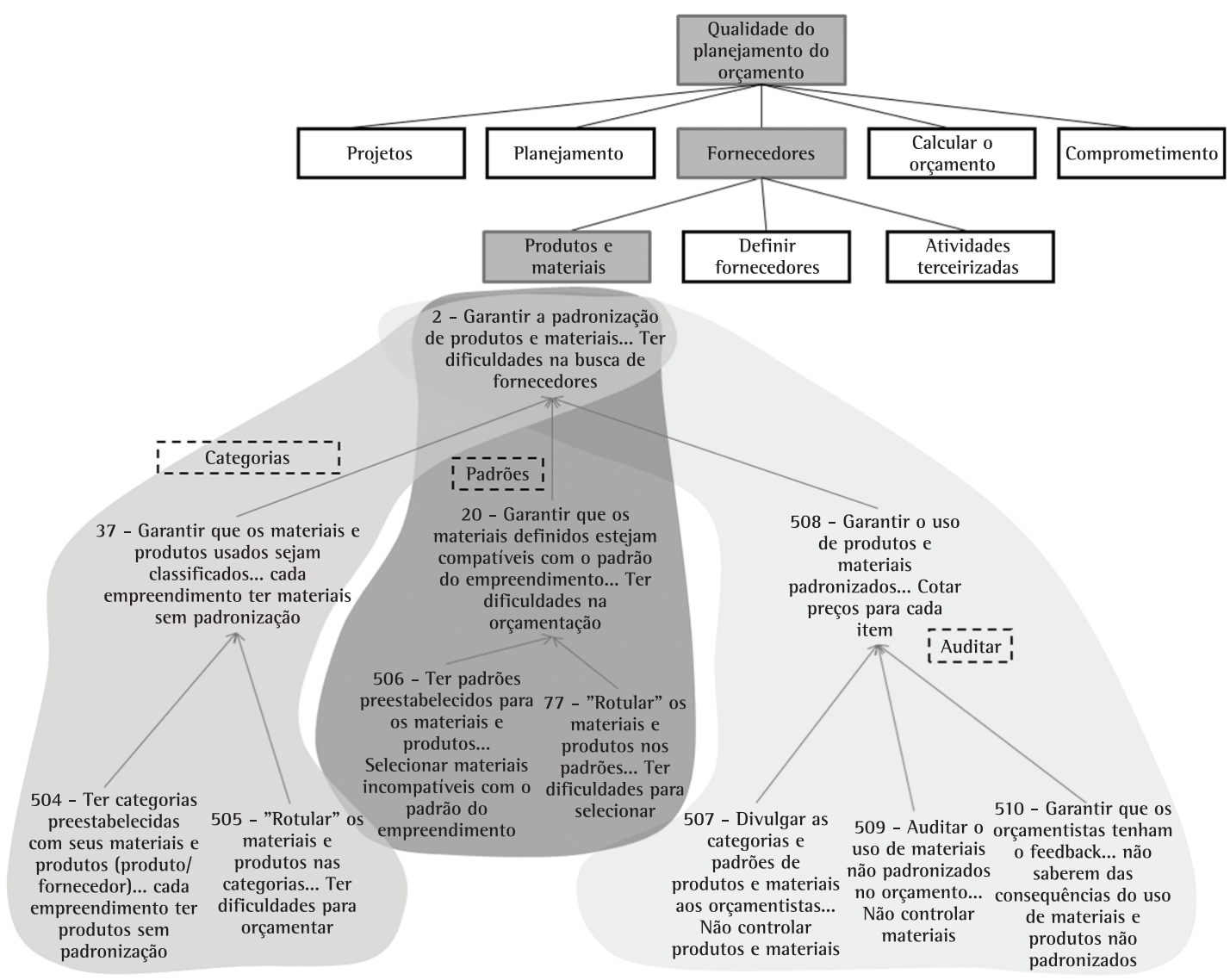

Figura 3. Mapas de relações meios-fim para o objetivo estratégico "produtos e materiais".

(PVF 5). Com base nos elementos do nível inferior da estrutura hierárquica de valor é iniciado o processo de construção dos descritores.

Aqui, os descritores estão relacionados a uma escala de medida (escala ordinal) que possibilita associar os valores do decisor às propriedades do objeto, representando o que ele considera relevante ser mensurado no critério abordado. Dada a complexidade natural dessa associação, empregam-se instrumentos científicos para sua realização (KEENEY; RAIFFA, 1976; KEENEY, 1992). A metodologia MCDA-C utiliza-se de mapas cognitivos para esse processo.

Com base no conhecimento gerado até este momento, desenvolve-se o descritor, podendo ele ser: qualitativo, gráfico, pictórico ou composto por símbolos alfanuméricos (BANA E COSTA et al., 1999; ENSSLIN et al., 2010).

Além disso, o decisor identificou dois níveis de referência: superior, nível acima do qual o desempenho é considerado excelente, e inferior, nível abaixo do qual o desempenho é considerado comprometedor.
A Figura 4 apresenta a estrutura hierárquica de valor com o PVF "produtos e materiais" com seus PVEs e descritores.

Concluída a construção da estrutura hierárquica de valor e dos descritores, a fase de estruturação do modelo é finalizada e se inicia a fase de avaliação.

\subsection{Avaliação}

Nesta seção será apresentado como ocorre a integração do modelo em escalas cardinais.

\subsubsection{Análise de independência}

De acordo com a MCDA-C, as taxas de compensação utilizadas na integração devem ser constantes; com isso, é necessário que os critérios sejam independentes (LACERDA; ENSSLIN; ENSSLIN, 2010).

Dessa forma, todos os descritores do modelo foram testados observando a independência preferencial mútua exposta por Keeney (1992), sendo constatados 


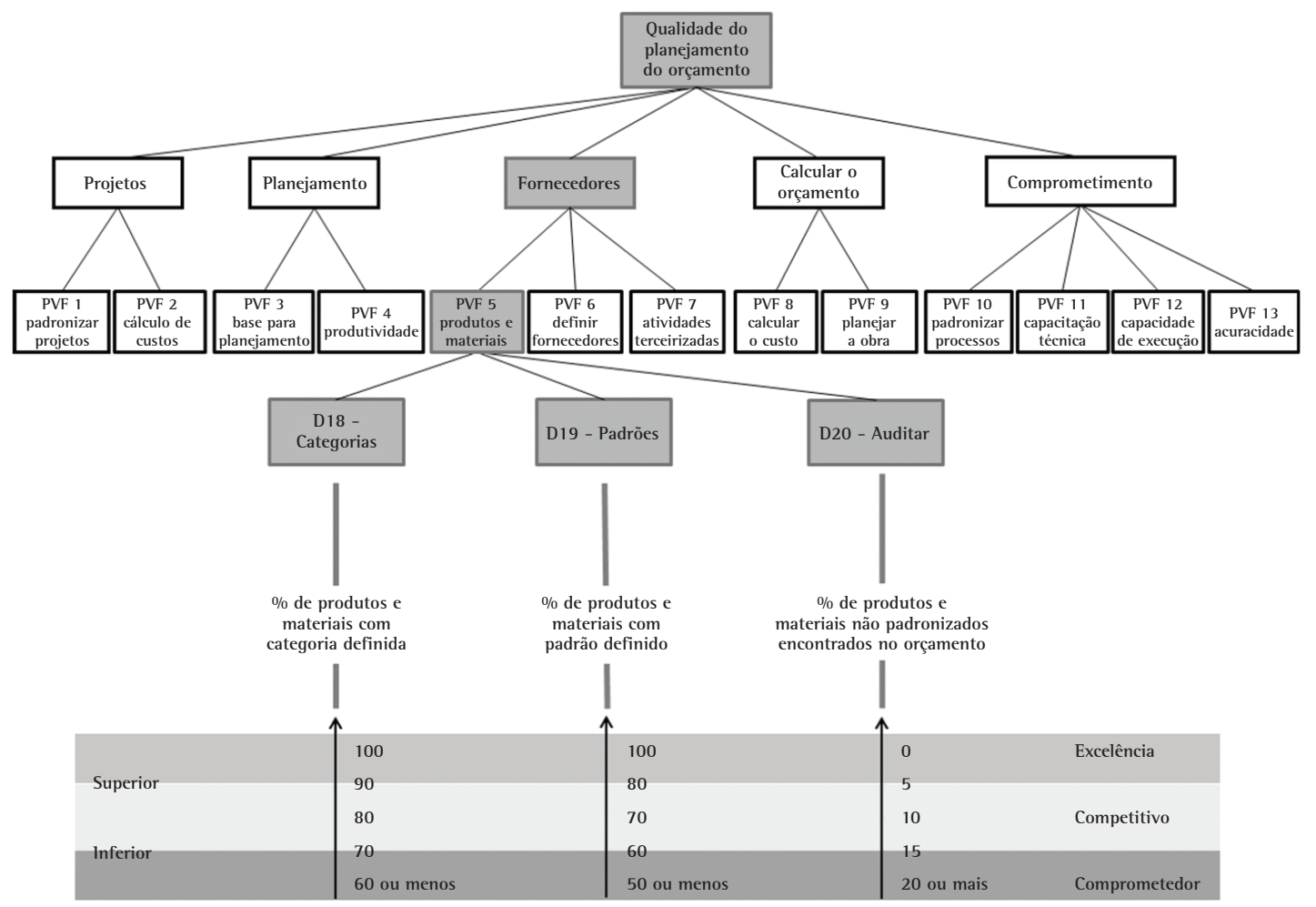

Figura 4. Estrutura hierárquica de valor do PVF 5 "produtos e materiais” com seus PVEs e descritores.

como mutuamente preferencialmente independentes, ordinal e cardinalmente.

\subsubsection{Construção de funções de valores e identificação das taxas de compensação}

Nas seções seguintes estão os procedimentos para determinar funções de valores e taxas de compensação.

Funções de valor

A fim de transformar as escalas ordinais em escalas cardinais, Ensslin, Montibeller e Noronha (2001) apontam alguns métodos, tais como: pontuação direta, bissecção, Macbeth, dentre outros. A MCDA-C é congruente com todos esses métodos apontados para transformar as escalas ordinais em cardinais. Porém, dada sua fundamentação teórica, representatividade e reconhecimento prático, os autores desta pesquisa optaram pelo método MACBETH para realizar essa atividade no presente artigo.

0 método Macbeth permite a avaliação de opções mediante comparações qualitativas em termos de suas diferenças de atratividade em múltiplos critérios (BANA E COSTA; VANSNICK, 1995).

A matriz de julgamentos, exibida na Figura 5, é construída a partir das respostas do decisor sobre a diferença de atratividade entre os diferentes níveis da escala ordinal e permite que o software M-Macbeth determine a função de valor que irá transformar a escala ordinal em cardinal.

Já a Figura 6 exibe o conjunto de escalas cardinais $V(a)$, construídas para o ponto de vista fundamental 5 - "produtos e materiais", bem como as escalas ordinais a originais.

A construção das funções de valor relacionada aos descritores permite a mensuração cardinal de cada um dos aspectos identificados.

Contudo, para a integração desses critérios, se faz necessário identificar o quanto cada critério individual contribui para o desempenho global do orçamento. Isso requer a identificação das taxas de compensação.

Taxas de compensação

Para a determinação das taxas de compensação foi aplicado o método de comparação par-a-par disponivel através do software Macbeth.

Como ilustração serão determinadas as taxas de compensação para os critérios D18 - "categorias", D19 - "padrões" e D 20 - "auditar", que permitem a mensuração do PV 5 - "produtos e materiais" (vide Figura 6).

Nesse método, para que o decisor expresse seus julgamentos de valor, é necessário desenvolver alternativas que representem a mudança do nível inferior para o nível superior em cada um dos critérios, além de 
uma alternativa com desempenho inferior em todos os critérios abrangidos, conforme ilustrado na Figura 7.

Em seguida, as alternativas identificadas são ordenadas segundo o juízo preferencial do decisor, e, pela utilização da comparação par-a-par do software Macbeth, obtêm-se as taxas de compensação.

Assim, foi possivel determinar as taxas de compensação para os PVFs e PVEs, conforme ilustrado

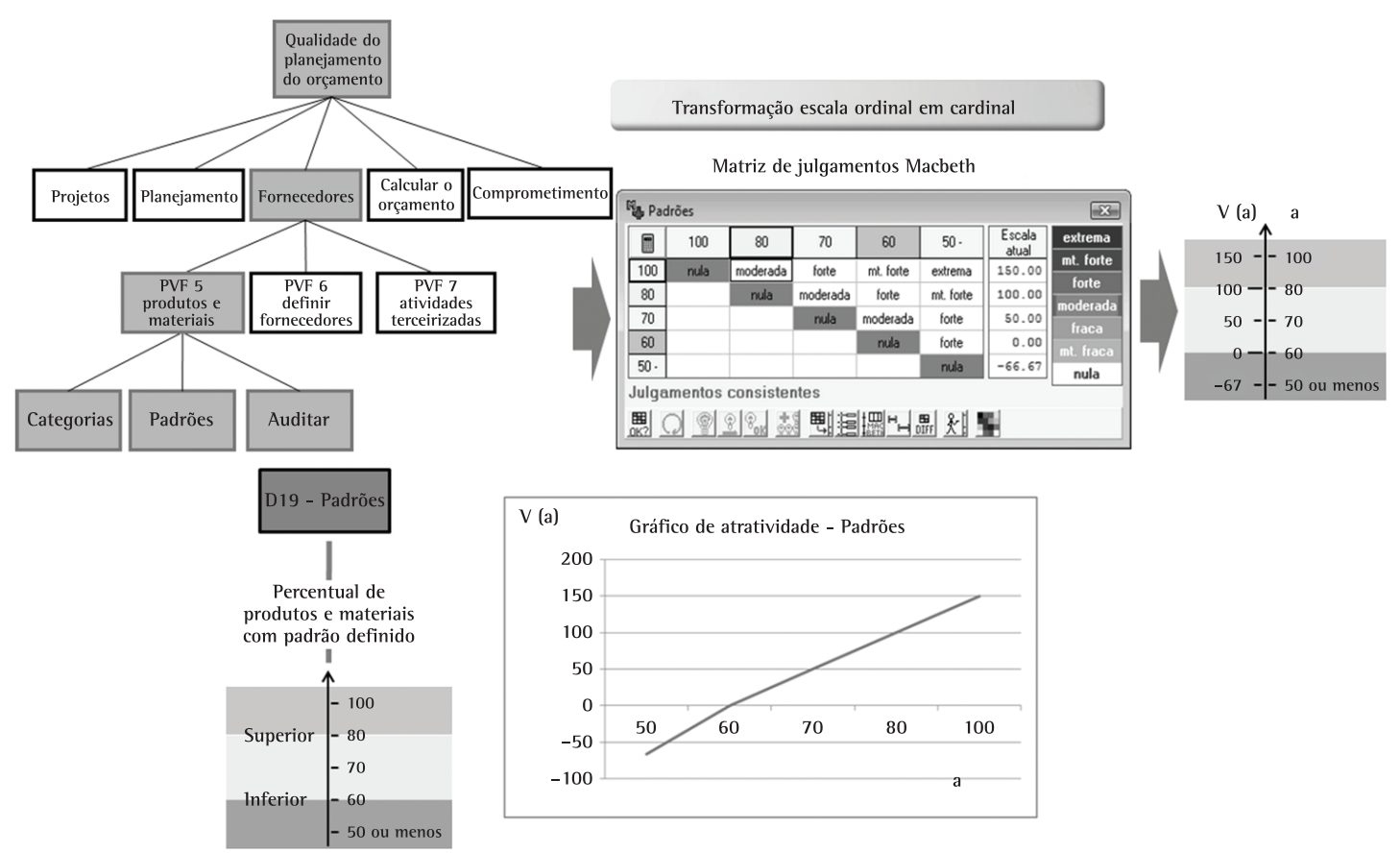

Figura 5. Transformação do descritor D18 categorias em função de valor por meio do método Macbeth.

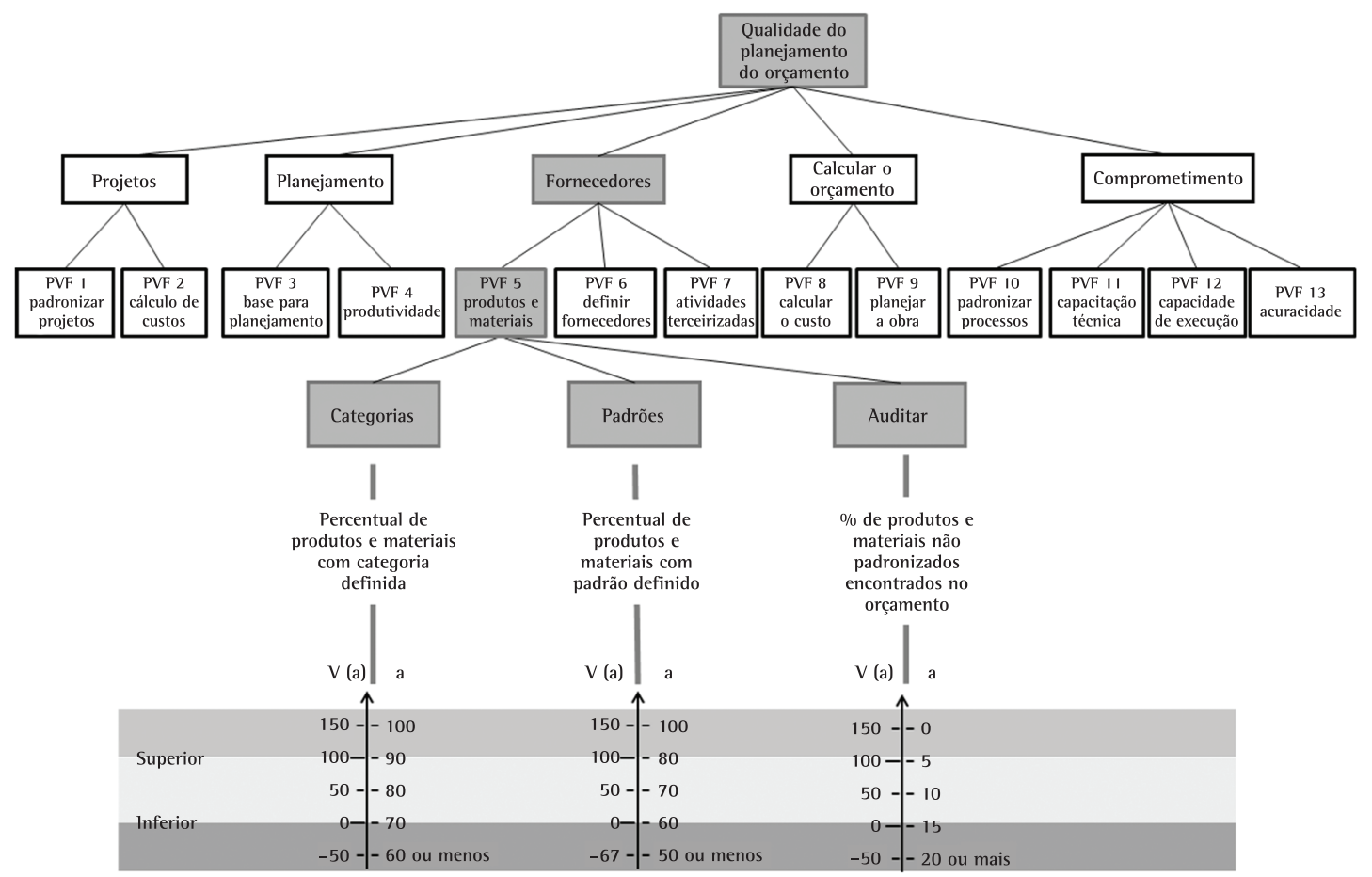

Figura 6. Escalas cardinais do PVF 5 - "produtos e materiais". 


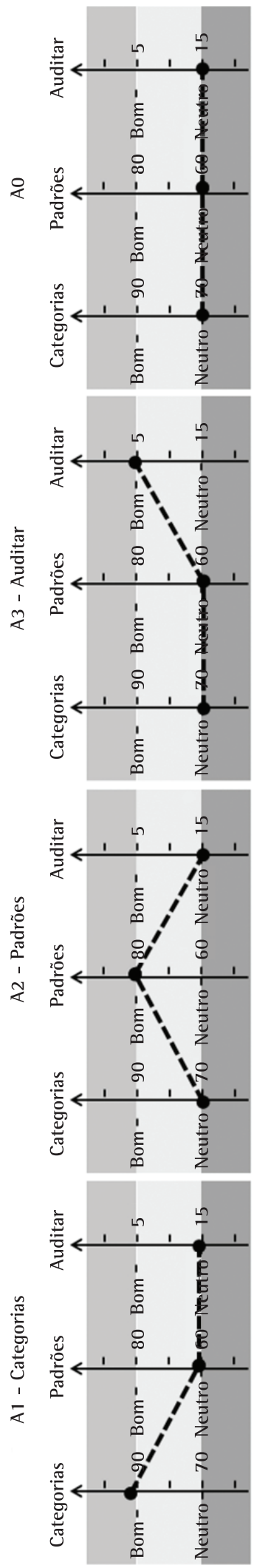

Figura 7. Alternativas potenciais para a determinação das taxas de compensação. na Figura 8 e partir para a dedução da equação do valor global do modelo multicritério.

Função de valor global do modelo

Com o conhecimento do contexto gerado até o momento, pode-se deduzir a equação para determinação do valor de qualquer ponto de vista do modelo. Retomando o exemplo do item anterior, a equação (1) do PVF 5 "produtos e materiais" é dada por:

$\mathrm{V}_{\text {PVF5(a) }}=0,42 \times \mathrm{V}_{\mathrm{D} 18(\mathrm{a})}+0,29 \times \mathrm{V}_{\mathrm{D} 19(\mathrm{a})}+0,29 \times \mathrm{V}_{\mathrm{S} 20(\mathrm{a})}$

Onde as constantes são as taxas de compensação relativas aos descritores (observe a Figura 9).

Assim, a equação genérica para cada ponto de vista fundamental será (Equação 2):

$$
V_{P V F K}(a)=\sum_{i=1}^{n_{k}} W_{i, k} \times V_{i, k}(a)
$$

onde:

- $\mathrm{V}_{\mathrm{PVFK}}(\mathrm{a})$ : valor global da ação a do $\mathrm{PVF}_{\mathrm{K}}$, para $\mathrm{K}=1,2, \ldots, \mathrm{m}$;

- $W_{i, k}$ : taxa de substituição do critério $i, i=1, \ldots, n$, do $\mathrm{PVF}_{\mathrm{k}}$, para $\mathrm{k}=1,2, \ldots, \mathrm{m}$;

- $W_{i, k}$ (a): valor parcial da ação a do critério $i, i=1, \ldots, n$, do $\mathrm{PVF}_{\mathrm{k}}$, para $\mathrm{k}=1, \ldots, \mathrm{m}$;

- a: nível de desempenho atingido no critério com a ação a;

- $\mathrm{n}_{\mathrm{k}}$ : número de critérios do $\mathrm{PVF}_{\mathrm{k}}$, para $\mathrm{k}=1,2, \ldots, \mathrm{m}$;

- m: número de PVF's do modelo global

Para ilustrar, a equação para o PVF 5 "produtos e materiais” é dada pela equação (3), na qual as constantes utilizadas são as próprias taxas de compensação referentes a cada ponto de vista.

$\mathrm{V}_{\text {Produtos e materiais }}=0,42 \times \mathrm{V}_{\text {Categorias }}$

$+0,29 \times V_{\text {Padrões }}+0,29 \times V_{\text {Auditar }}$

Com a função de valor global construída, o modelo está apto a ser empregado como apoio ao processo de gestão de orçamentos.

\subsubsection{Identificação do perfil de impacto das alternativas}

\section{Determinação do status quo}

A determinação do status quo do PVF "produtos e materiais" é apresentada na Figura 9. Para cada critério de avaliação, identificou-se o desempenho da empresa (a) na construção do orçamento do empreendimento A. Então, com a aplicação da função de valor obteve-se a pontuação $V(a)$ correspondente na escala cardinal. Como resultado da aplicação da Equação 3, obteve-se 


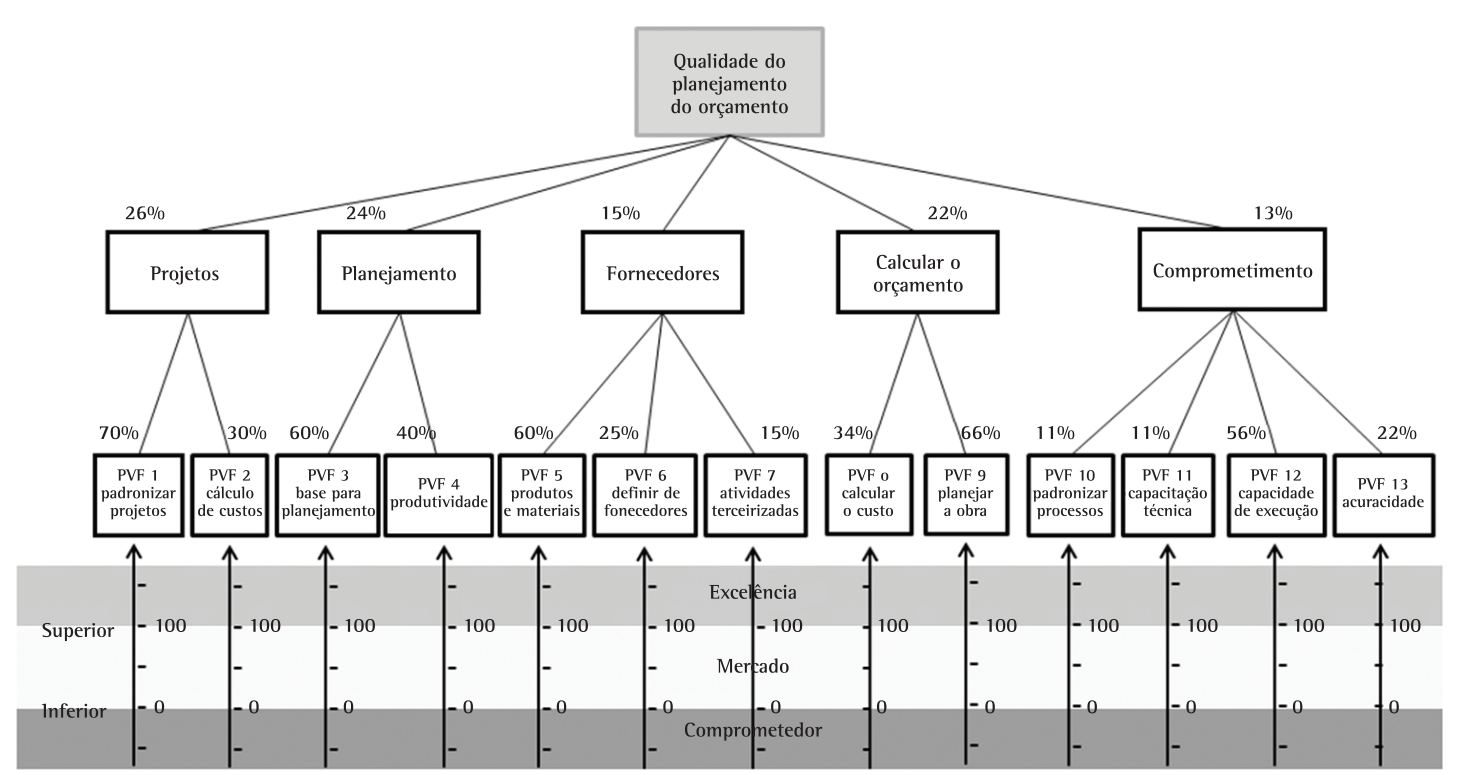

Figura 8. Estrutura hierárquica de valor global com as respectivas taxas de compensação.

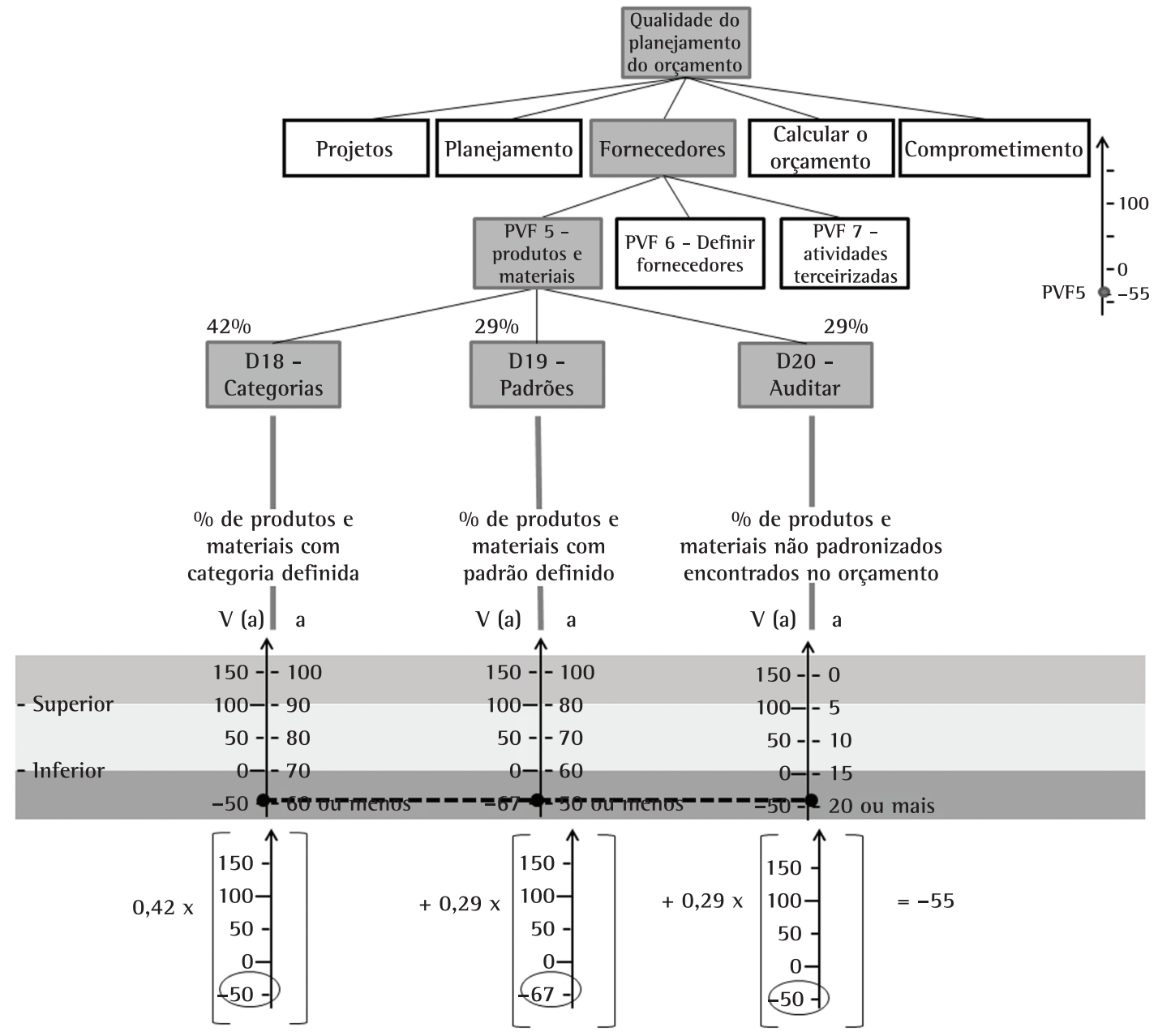

Figura 9. Determinação do status quo do PVF “atividades terceirizadas”. 
a pontuação do PVF 5 (-55 pontos), indicando um desempenho comprometedor para o PVF.

A determinação do status quo a partir de um processo de orçamento recente possibilitou a identificação dos pontos fortes e fracos da empresa em relação ao problema analisado. Essa análise indicou que, dos 13 objetivos estratégicos destacados na Figura 8, apenas quatro possuíam desempenho competitivo.

Assim, o modelo de avaliação possibilitou identificar a contribuição de cada um dos aspectos no contexto de forma global.

\subsection{Recomendações}

Uma vez determinado o status quo do processo de orçamentação, o decisor identificou os PVFs com pior desempenho e pôde elencar, a partir destes, os focos de desenvolvimento de planos de ações com o intuito de contribuir com a melhoria do desempenho da empresa em relação ao processo de orçamentação.

Os focos identificados foram: (i) fornecedores; (ii) padronização; e (iii) produtividade, conforme ilustrado no Quadro 4.

Em seguida, os critérios de avaliação que seriam afetados por esses planos de ação foram identificados e a análise desses critérios (descritores) formou a base para a identificação das ações necessárias para que os objetivos estratégicos estabelecidos fossem atingidos.

Com base nas ações de melhoria estabelecidas, o decisor identificou, para cada critério, o desempenho a ser alcançado pelo desenvolvimento da ação.

0 decisor estimou o custo financeiro de cada um dos planos, considerando apenas o custo dos recursos humanos que seriam necessários para sua implementação e manutenção durante um período de tempo (seis meses), para poder estabelecer uma comparação custo-benefício.
Por sugestão dos facilitadores, um quarto plano de ações (Plano Geral) foi desenvolvido, com o objetivo de englobar todas as ações individuais e distintas dos três planos identificados anteriormente. 0 Quadro 4 apresenta uma visão geral dos planos de ação.

\subsubsection{Formulação das recomendações}

A etapa de recomendações objetiva auxiliar o decisor a perceber as melhores formas de otimizar o desempenho do objeto avaliado, além de oportunizar a compreensão das consequências dessas ações em seus objetivos estratégicos.

Alguns casos requerem a compreensão de o quanto o desempenho das alternativas se altera em função da modificação da taxa de substituição do PVF ou PVE analisado. A este procedimento se dá nome de análise de sensibilidade.

A análise de sensibilidade do modelo estruturado mostrou que a alternativa "padronização" é robusta a eventuais variações na taxa de substituição do PVF "produtos e materiais" e evidenciou a predominância do plano de ação onde as ações envolviam um maior número de descritores do PVF analisado.

Ressalta-se que a etapa de recomendações é um instrumento de apoio que visa auxiliar o decisor a construir ações e avaliar suas consequências, e não ditar as ações que devem ser implementadas.

A Figura 10 ilustra um caso de formulação de recomendações. Como pode ser observado, a ação proposta foi decomposta nos passos necessários para sua implementação, com o objetivo de elevar a performance do PVE de um desempenho comprometedor ( $20 \%$ ou mais de variação) para um desempenho de excelência (5\% de variação).

A comparação dos planos de ação permite ao tomador de decisão visualizar as consequências que cada plano teria sobre a avaliação global do processo de orçamentação de projetos e a relação

Quadro 4. Planos de ações propostos com seus respectivos custos e pontos obtidos.

\begin{tabular}{|c|c|c|c|c|c|}
\hline Plano & Objetivo & $\begin{array}{l}\text { Resultado (status quo } \\
\quad \text { inicial }=-36 \text { ) }\end{array}$ & $\begin{array}{l}\text { Pontos } \\
\text { obtidos }\end{array}$ & Custo & $\begin{array}{l}\text { Custo por } \\
\text { ponto }\end{array}$ \\
\hline Fornecedores & $\begin{array}{l}\text { Melhorar o relacionamento com os fornecedores } \\
\text { por meio da melhoria da qualidade da prestação } \\
\text { de serviços, de preços e do fornecimento de } \\
\text { materiais e produtos. }\end{array}$ & -17 & 19 & 30.000 & 1.579 \\
\hline Produtividade & $\begin{array}{l}\text { Melhorar a qualidade do cálculo de custos } \\
\text { de execução de serviços e projetos, a partir } \\
\text { de informações de produtividade da própria } \\
\text { empresa. }\end{array}$ & 18 & 54 & 56.000 & 1.037 \\
\hline Padronização & $\begin{array}{l}\text { Padronizar os processos internos da empresa } \\
\text { a fim de melhorar suas definições, execução e } \\
\text { controle. }\end{array}$ & 38 & 74 & 103.000 & 1.392 \\
\hline Geral & $\begin{array}{l}\text { Melhoria geral da empresa pela aplicação de } \\
\text { todas as distintas ações dos três planos acima. }\end{array}$ & 95 & 131 & 132.000 & 1.008 \\
\hline
\end{tabular}




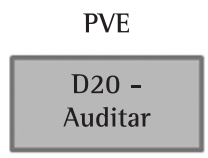

I

$\%$ de produtos e materiais não padronizados encontrados no orçamento

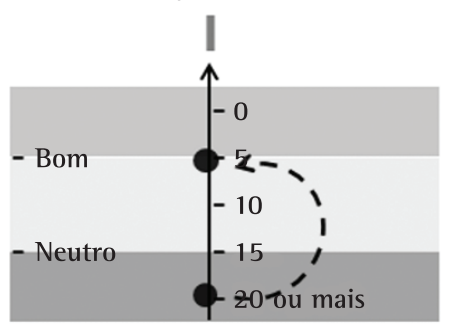

Ação: Criar categorias e padrões de produtos e materiais e classificar os produtos e materiais nas categorias e padrões definidos.

- Criar categorias e padrões para produtos e materiais;

- Relacionar todos os produtos e materiais po categoria e padrão;

- Divulgar a classificação dos produtos e materiais por categoria e padrão;

- Auditar produtos e materiais utilizados que estão fora das categorias e padrões estabelecidos;

- Manter as categorias e padrões atualizados.

Figura 10. Impacto do plano de ações no descritor do PVE auditar.

custo-benefício de cada plano. Embora o quarto plano de ações (Plano Geral) apresente o melhor custo por ponto foi obtido, o decisor identificou o plano de ação "produtividade" como o mais provável de ser aprovado pela direção, pois este apresenta um baixo custo (o segundo menor custo) e um significativo impacto sobre a avaliação global (um aumento de 54 pontos na avaliação global, com um custo total 66\% menor que o Plano Geral e um custo-benefício similar a este, como mostrado no Quadro 4).

0 conhecimento gerado no decisor, pela utilização da metodologia MCDA-C e do modelo de avaliação para o processo de orçamentação desenvolvido, permitiu identificar: (1) as ações necessárias para melhoria do contexto avaliado; (2) os fatores (critérios) afetados pelas ações propostas; (3) a prioridade com que essas áreas devem ser abordadas; e (4) o impacto ou consequência de ações nos níveis operacionais, táticos e estratégicos.

\section{Considerações finais}

0 modelo multicritério de apoio à decisão, desenvolvido segundo a metodologia MCDA-C, permitiu identificar, mensurar e integrar os aspectos considerados suficientes e relevantes pelo decisor que influenciam os desvios de orçamento de um empreendimento em uma construtora de Santa Catarina. A avaliação do modelo permitiu a identificação de ações de melhoria que conduziram à evolução do processo de orçamentação utilizado por essa construtora, eliminando ou minimizando os desvios causadores de imprecisão e erros existentes nesse processo.

Assim, a pergunta de pesquisa que norteou este trabalho e aqui transcrita - "Como avaliar a qualidade de um orçamento e se valer desse conhecimento para propor ações preventivas de desvios?" - foi respondida por meio dos procedimentos preconizados pela MCDA-C explicados no estudo de caso, atendendo aos dois objetivos específicos desta pesquisa.

A construção de conhecimento oportunizada pela aplicação da MCDA-C permitiu ao decisor perceber o valor do desempenho global de um processo de orçamentação, além de apresentar de forma individual o desempenho de cada aspecto relevante identificado, com vistas a explicitar pontos críticos no processo.

0 modelo de avaliação, construído com total envolvimento do decisor em todas as suas etapas, forneceu à empresa e ao decisor o conhecimento sobre o que é relevante em um processo de orçamentação de um novo empreendimento, proporcionando o estabelecimento de ações estratégicas contínuas para alavancar a melhoria do desempenho do processo de forma global.

Assim, a metodologia MCDA-C respondeu à pergunta de pesquisa e atendeu ao objetivo geral e aos específicos, criando conhecimento no decisor sobre o contexto avaliado e propiciando condições para a estruturação de ações visando à melhoria do desempenho da empresa no processo avaliado.

Como recomendação para trabalhos futuros, sugere-se que outros processos dentro da área de construção civil sejam avaliados com a utilização da metodologia MCDA-C de forma a demonstrar a abrangência dessa metolodogia em qualquer processo decisório. Ressalta-se que a metodologia MCDA-C, sendo aplicada a partir dos pontos de vista e preferências de outro decisor, ainda que no mesmo processo decisório, traria resultados diferentes dos aqui apresentados, tendo em vista a personalização do modelo sob a perspectiva de um decisor específico, fator este que se traduz em uma limitação desta pesquisa. 


\section{Referências}

Al LIN TEO, E.; YEAN YNG LING, F. Developing a model to measure the effectiveness of safety management systems of construction sites. Building and Environment, v. 41, n. 11, p. 1584-1592, 2006. http://dx.doi.org/10.1016/j. buildenv.2005.06.005

ALMEIDA-DIAS, J.; FIGUEIRA, J. R.; ROY, B. A multiple criteria sorting method where each category is characterized by several reference actions: The Electre Tri- $n C$ method. European Journal of Operational Research, v. 217, n. 3, p. 567-579, 2012. http://dx.doi.org/10.1016/j. ejor.2011.09.047

ANTON, J. M.; GRAU, J. B. Madrid-Valencia high-speed rail line: A route selection. Proceedings of the Institution of Civil Engineers: Transport, v. 157, n. 3, p. 153-161, 2004.

AZAD, S. A. K. Emotional intelligence (EI) and performance improvement system (PIS) in construction industry using digital monitoring smart test: A key for effective construction organization. International Journal for Housing Science and Its Applications, v. 35, n. 3, p. 159169, 2011.

BANA E COSTA, C. A. Structuration, Construction et Exploitation dún Modèle Multicritère d'Aide à la Decision. 1992. Thèse (Doctorat en Ingénierie de Systèmes)-Instituto Superior Técnico, Universidade Técnica de Lisboa, Lisboa, 1992.

BANA E COSTA, C. A. et al. Decision Support Systems in action: Integrated application in a multicriteria decision aid process. European Journal of Operational Research, v. 113, n. 2, p. 315-335, 1999. http://dx.doi.org/10.1016/ S0377-2217(98)00219-7

BANA E COSTA, C. A.; VANSNICK, J. C. Uma nova abordagem ao problema da construção de uma função de valor cardinal: MACBETH. Investigação Operacional, v. 15, 1995.

BANAITIENE, N. et al. Evaluating the life cycle of a building: A multivariant and multiple criteria approach. OmegaInternational Journal of Management Science, v. 36, n. 3, p. 429-441, Jun 2008. http://dx.doi.org/10.1016/j. omega.2005.10.010

BARZILAl, J. On the foundations of measurement. In: IEEE INTERNATIONAL CONFERENCE ON SYSTEMS, MAN AND CYBERNETICS, 2001, Tucson. Proceedings... IEEE, 2001. p. 401-406.

BORTOLUZZI, S. C.; ENSSLIN, S. R.; ENSSLIN, L. Avaliação de Desempenho dos Aspectos Tangíveis e Intangiveis da Área de Mercado: estudo de caso em uma média empresa industrial. RBGN - Revista Brasileira de Gestão de Negócios, v. 12, n. 37, p. 425-446, 2010.

CHEUNG, S. O.; SUEN, H. C. H. A multi-attribute utility model for dispute resolution strategy selection. Construction Management and Economics, v. 20, n. 7, p. 557-568, 2002. http://dx.doi.org/10.1080/01446190210157568

ClOFFl, D. F.; KHAMOOSHI, H. A practical method of determining project risk contingency budgets. Journal of the Operational Research Society, v. 60, n. 4, p. 565571, Apr 2009. http://dx.doi.org/10.1057/palgrave. jors.2602586

CORONADO, M. et al. Estimation of construction and demolition waste (C\&DW) generation and multicriteria analysis of C\&DW management alternatives: A case study in Spain. Waste and Biomass Valorization, v. 2, n. 2, p. 209-225, 2011. http://dx.doi.org/10.1007/s12649-011-9064-8
COSTA, D. B. et al. Benchmarking Initiatives in the Construction Industry: Lessons Learned and Improvement Opportunities. Journal of Management in Engineering, v. 22, n. 4, p. 158-167, 2006. http://dx.doi.org/10.1061/ (ASCE)0742-597X(2006)22:4(158)

DA ROSA, F. S. et al. Gestão da evidenciação ambiental: Um estudo sobre as potencialidades e oportunidades do tema. Engenharia Sanitária e Ambiental JCR, v. 16, n. 2, p. 157-166, 2011. http://dx.doi.org/10.1590/S141341522011000200009

DA ROSA, F. S. et al. Environmental disclosure management: a constructivist case. Management Decision, v. 50, n. 6, p. 1117-1136, 2012. http://dx.doi. org/10.1108/00251741211238364

DE MORAES, L. et al. The multicriteria analysis for construction of benchmarkers to support the Clinical Engineering in the Healthcare Technology Management. European Journal of Operational Research, v. 200, n. 2, p. 607615, 2010. http://dx.doi.org/10.1016/j.ejor.2009.01.018

DVIR, D.; LECHLER, T. Plans are nothing, changing plans is everything: the impact of changes on project success. Research Policy, v. 33, n. 1, p. 1-15, 2004. http://dx.doi. $\operatorname{org} / 10.1016 /$ j.respol.2003.04.001

EDEN, C.; JONES, S.; SIMMS, D. Messing about in Problems. $R \& D$ Management, v. 15, n. 3, p. 255-255, 1985. http:// dx.doi.org/10.1111/j.1467-9310.1985.tb00550.x

ENSSLIN, L. Processo Decisório e Aspectos Cognitivos. In: SIMPÓSIO DE PESQUISA OPERACIONAL E LOGÍSTICA DA MARINHA, 12., 2009, Rio de Janeiro. Anais... Rio de Janeiro: SPOLM, 2009.

ENSSLIN, L.; DUTRA, A.; ENSSLIN, S. R. MCDA: a constructivist approach to the management of human resources at a governmental agency. International Transactions in Operational Research, v. 7, n. 1, p. 79-100, 2000. http:// dx.doi.org/10.1111/j.1475-3995.2000.tb00186.x

ENSSLIN, L. et al. Avaliação do Desempenho de Empresas Terceirizadas com o Uso da Metodologia Multicritério de Apoio à Decisão- Construtivista. Revista Pesquisa Operacional, v. 30, n. 1, p. 125-152, 2010.

ENSSLIN, L.; MONTIBELLER, N. G.; NORONHA, S. M. Apoio à decisão: metodologias para estruturação de problemas e avaliação multicritério de alternativas. Florianópolis: Insular, 2001.

FAN, M.; LIN, N. P.; SHEU, C. Choosing a project risk-handling strategy: An analytical model. International Journal of Production Economics, v. 112, n. 2, p. 700-713, Apr 2008. http://dx.doi.org/10.1016/j.jpe.2007.06.006

FARRIS, J. A. et al. Evaluating the relative performance of engineering design projects: A case study using data envelopment analysis. IEEE Transactions on Engineering Management, v. 53, n. 3, p. 471-482, Aug 2006. http:// dx.doi.org/10.1109/TEM.2006.878100

FREJ, T. A.; ALENCAR, L. H. Fatores de sucesso no gerenciamento de mútiplos projetos na construção civil em Recife. Produção, v. 20, p. 322-334, 2010. http:// dx.doi.org/10.1590/S0103-65132010005000043

FRENETTE, C. D. et al. Multicriteria decision analysis applied to the design of light-frame wood wall assemblies. Journal of Building Performance Simulation, v. 3, n. 1, p. 33-52, 2010. http://dx.doi.org/10.1080/19401490903395133

GÜERECA, L. P. et al. Fuzzy approach to life cycle impact assessment: An application for biowaste management 
systems. International Journal of Life Cycle Assessment, v. 12, n. 7, p. 488-496, 2007.

KAPLIŃSKl, O. Development And Usefulness Of Planning Techniques And Decision-Making Foundations On The Example Of Construction Enterprises In Poland. Technological and Economic Development of Economy, v. 14, n. 4, p. 492-502, 2008. http://dx.doi. org/10.3846/1392-8619.2008.14.492-502

KEENEY, R. L. Value-Focused Thinking: A Path to Creative Decisionmaking. Harvard University Press, 1992.

KEENEY, R. L.; RAIFFA, H. Decisions with Multiple Objectives: Preferences and Value Trade-offs. New York: Wiley, 1976.

KOG, Y. C.; LOH, P. K. Critical success factors for different components of construction projects. Journal of Construction Engineering and Management, v. 138, n. 4, p. 520-528, 2012. http://dx.doi.org/10.1061/(ASCE) C0.1943-7862.0000464

K00, C.-W. et al. A Study On The Development Of A Cost Model Based On The Owner's Decision Making At The Early Stages Of A Construction Project. International Journal of Strategic Property Management, v. 14, n. 2, p. 121-137, 2010. http://dx.doi.org/10.3846/ ijspm.2010.10

KRAWCZYŃSKA, A. Design of work execution system for build-in self compacting concrete construction. Projektowanie organizacji wykonania monolitycznych konstrukcji betonowych $w$ technologii SCC, n. 91, p. 247-257, 2008.

KUMAR DEY, P. Decision support system for risk management: a case study. Management Decision, v. 39, n. 8, p. 634-649, 2001. http://dx.doi. org/10.1108/00251740110399558

LACERDA, R. T. O.; ENSSLIN, L.; ENSSLIN, S. R. Um estudo de caso sobre gerenciamento de portfólio de projetos e apoio a decisão multicritério. Revista Gestão Industrial, v. 6, n. 1, p. 01-28, 2010.

LACERDA, R. T. 0.; ENSSLIN, L.; ENSSLIN, S. R. A Performance Measurement Framework in Portfolio Management: A Constructivist Case. Management Decision, v. 49, n. 4, p. 1-15, 2011a. http://dx.doi. org/10.1108/00251741111126530

LACERDA, R. T. 0.; ENSSLIN, L.; ENSSLIN, S. R. A Performance Measurement View of IT Project Management. The International Journal of Productivity and Performance Management, v. 60, n. 2, p. 132-151, 2011b. http:// dx.doi.org/10.1108/17410401111101476

LACERDA, R. T. 0.; ENSSLIN, L.; ENSSLIN, S. R. Uma Análise Bibliométrica da Literatura Sobre Estratégia e Avaliação De Desempenho. Gestão \& Produção, v. 19, n. 1, p. 59-78, 2012. http://dx.doi.org/10.1590/S0104530X2012000100005

LANDRY, M. A note on the concept of problem. Organization Studies, v. 16, p. 315-343, 1995 . http://dx.doi. org/10.1177/017084069501600206

LOPES, 0. C.; LIBRELOTTO, L. 1.; AVILA, A. V. Orçamento de Obras. Florianópolis: Universidade do Sul de Santa Catarina - UNISUL, 2003. Unpublished Work.

MAQSOOD, T.; WALKER, D. H. T.; FINEGAN, A. D. Facilitating knowledge pull to deliver innovation through knowledge management: A case study. Engineering, Construction and Architectural Management, v. 14, n. 1, p. 94-109, 2007. http://dx.doi.org/10.1108/09699980710717007
MATEUS, R.; FERREIRA, J. A.; CARREIRA, J. Multicriteria decision analysis (MCDA): Central Porto high-speed railway station. European Journal of Operational Research, v. 187, n. 1, p. 1-18, 2008. http://dx.doi. org/10.1016/j.ejor.2007.04.006

MONTIBELLER, G. et al. Reasoning maps for decision aid: an integrated approach for problem-structuring and multi-criteria evaluation. Journal of the Operational Research Society, v. 59, p. 575-589, 2008. http://dx.doi. org/10.1057/palgrave.jors.2602347

MOTA, C. M. D. M.; DE ALMEIDA, A. T. Método multicritério ELECTRE IV-H para priorizaç ão de atividades em projetos. Pesquisa Operacional, v. 27, n. 2, p. 247-269, 2007. http://dx.doi.org/10.1590/S0101-74382007000200004

MOTA, C. M. D. M.; DE ALMEIDA, A. T.; ALENCAR, L. H. A multiple criteria decision model for assigning priorities to activities in project management. International Journal of Project Management, v. 27, n. 2, p. 175-181, 2009. http://dx.doi.org/10.1016/j.jproman.2008.08.005

OYETUNJI, A. A.; ANDERSON, S. D. Relative effectiveness of project delivery and contract strategies. Journal of Construction Engineering and Management, v. 132, n. 1, p. 3-13, 2006. http://dx.doi.org/10.1061/(ASCE)07339364(2006)132:1(3)

POLLACK-JOHNSON, B.; LIBERATORE, M. J. Incorporating quality considerations into project time/cost tradeoff analysis and decision making. IEEE Transactions on Engineering Management, v. 53, n. 4, p. 534-542, Nov. 2006. http://dx.doi.org/10.1109/TEM.2006.883705

ROY, B. Decision science or decision-aid science? European Journal of Operational Research, v. 66, n. 2, p. 184-203, 1993. http://dx.doi.org/10.1016/03772217(93)90312-B

ROY, B. Multicriteria Methodology for Decision Aiding. Kluwer Academic Pub., 1996. http://dx.doi.org/10.1007/978-14757-2500-1

SHANIAN, A.; SAVADOGO, O. A methodological concept for material selection of highly sensitive components based on multiple criteria decision analysis. Expert Systems with Applications, v. 36, n. 2, part 1, p. 1362-1370, 2009.

STEVOVIC, S. M.; MILOVANOVIC, Z. D.; MILAJIC, A. V. New Methodological Approach in Techno-Economic and Environmental Optimization of Sustainable Energy Production. Thermal Science, v. 14, n. 3, p. 809819, 2010. http://dx.doi.org/10.2298/TSCl100510007S

SUTRISNA, M.; BARRETT, P. Applying rich picture diagrams to model case studies of construction projects. Engineering, Construction and Architectural Management, v. 14, n. 2, p. 164-179, 2007. http:// dx.doi.org/10.1108/09699980710731281

SZAJUBOK, N. K.; ALENCAR, L. H.; ALMEIDA, A. T. D. Modelo de gerenciamento de materiais na construção civi utilizando avaliação multicritério. Produção, v. 16, n. 2, p. 303-318, 2006. http://dx.doi.org/10.1590/S010365132006000200010

SZAJUBOK, N. K.; MOTA, C. M. D. M.; ALMEIDA, A. T. D. Uso do método multicritério ELECTRE TRI para classificação de estoques na construção civil. Pesquisa Operacional, v. 26 , n. 3, p. 625-648, 2006. http://dx.doi.org/10.1590/ S0101-74382006000300010

ULUBEYLI, S.; KAZAZ, A. A multiple criteria decision-making approach to the selection of concrete pumps. Journal of Civil Engineering and Management, v. 15, n. 4, 
p. 369-376, 2009. http://dx.doi.org/10.3846/13923730.2009.15.369-376

INSTITUTO UNIEMP. Fórum Permanente das Relações Universidade-Empresa. 2010. Disponível em: <http:// www.uniemp.br/seminarios>.

WINTER, M.; CHECKLAND, P. Soft systems - a fresh perspective for project management. Proceedings of the Institution of Civil Engineers: Civil Engineering, v. 156, n. 4, p. 187-192, 2003. http://dx.doi.org/10.1680/ cien.2003.156.4.187

XUE, X.; Ll, X.; SHEN, Q.; WANG, Y. An agent-based framework for supply chain coordination in construction.
Automation in Construction, v. 14, n. 3, p. 413-430, 2005. http://dx.doi.org/10.1016/j.autcon.2004.08.010

ZAMCOPÉ, F. C. et al. Modelo para avaliar o desempenho de operadores logísticos: um estudo de caso na indústria têxtil. Gestão \& Produção, v. 17, p. 693-705, 2010. http://dx.doi.org/10.1590/S0104-530X2010000400005

ZAVADSKAS, E. K.; USTINOVICHIUS, L.; STASIULIONIS, A. Multicriteria valuation of commercial construction projects for investment purposes. Journal of Civil Engineering and Management, v. 10, n. 2, p. 151166, 2004. http://dx.doi.org/10.1080/13923730.2004.9 636299

\title{
Model for performance evaluation: application on a budget of a construction work
}

\begin{abstract}
This work implements an exploratory approach of practical nature that uses the problems of diversion of a budget presented by a Brazilian construction company as an object of study, in order to present a process for building a multi-criteria evaluation model to support decisions about budgeting for a construction work. As an intervention tool, it makes use of the Methodology Multi-criteria Decision Support - Constructivist (MCDA-C), which led to the identification, organization, measurement, and integration of the factors judged relevant to the perception of the decision-maker. Finally, it brings a case study that illustrates the construction of a model that expanded the knowledge of the decision-maker about the problem, highlighting vulnerable situations in the budgeting process and providing opportunities for the development of improvement actions.
\end{abstract}

Keywords

Performance evaluation. Decision. Construction. Project management. 